\title{
Economic Impact Assessment of the Novel Coronavirus on Tourism and Trade in Kenya: Lessons from Preceding Epidemics
}

\author{
Kevin Wanjala \\ Egerton University, Kenya \\ Email:Wanjalakevin89@gmail.com \\ https://riiopenjournals.com/index.php/finance-economics-review
}

Doi: https://doi.org/10.38157/finance-economics-review.v2i1.57

Citation: Wanjala, K. (2020). Economic Impact Assessment of the Novel Coronavirus on Tourism and Trade in Kenya: Lessons from Preceding Epidemics. Finance \& Economics Review, 2(1), 1-10. Doi: https://doi.org/10.38157/finance-economics-review.v2i1.57

\section{Research Article}

\section{Abstract}

Purpose: This paper aims to assess the impact of contemporary Coronavirus Pandemic on tourism and trade with its potential implications on the Kenyan economy.

Method: The study considered the cases of Severe Acute Respiratory Syndrome (SARS), Middle East Respiratory Syndrome (MERS) and Ebola epidemics to provide an understanding of the possible impacts that the novel coronavirus pandemic could have on the economy.

Results: This study established that the demand and supply shocks of the pandemic will inevitably impact Kenya's economy specifically, the tourism and trade sectors. The Kenyan government has imposed several measures in an attempt to combat the spread of the coronavirus and cushion the country against a possible economic downturn. The study established that the policies imposed have largely focused on demand shock management.

Implications: To effectively minimize the impacts of the pandemic shocks on the economy, it will be prudent for the Kenyan government to design policy responses with a blend of short term and long term orientations. The policies should be multifaceted and their design should involve stakeholders from all the relevant sectors.

Keywords: Coronavirus, Covid-19, Trade, Tourism, Epidemic, Pandemic, Kenya

\section{Introduction}

The on-going coronavirus also known as the Covid-19 outbreak is causing widespread disruption in the economies across the globe. Having started in China's city of Wuhan in December 2019 it has since spread to other parts of the world and currently affecting 212 countries. As of $2^{\text {nd }}$ May 2020, the number of recorded cases were 3,267,184 and death toll stood at 229,971 (WHO, 2020). These statistics are an indication that the virus is spreading rapidly and has a higher infection rate per person compared to other virus outbreaks that have occurred in 
recent times (Eflein, 2020). The World Health Organization contends that the closest parallel to the current pandemic is the 1918 influenza pandemic, popularly known as the Spanish flu.

The Coronavirus pandemic has overstretched the resources of public sectors particularly of the worst affected countries. The health consequence of the pandemic are of primary concern with focus being on preventative and containment measures as well as equipping and preparing the global health care systems' capacity to confront the pandemic. Nonetheless, it is worth pointing out that, other than the health consequences, the pandemic will inevitably have an economic impact. Economic implications, however, play second fiddle to health implications nonetheless are still vital as they can play a key role in health outcomes. Secondly, the economic effects could stay with us even after the pandemic is averted, hence it is important to understand the possible implications in order to counter them. This paper seeks to find out the likely economic impact that the pandemic might have on a developing country with a not so robust healthcare system. This is in a bid to offer policy direction for the country once it's hit by the severity of the pandemic.

So far no study has attempted to study the potential impact of the pandemic on developing countries, let alone African economies. A few studies have however, been conducted on the potential global impact. Castro (2020) on fiscal policy during pandemic using a New Kynesian Dynamic Stochastic General Equilibrium (DSGE) model and Mckibbin and Fernando (2020) on the global macroeconomic of Covid-19 using a hybrid of DSGE and Computable General Equilibrium Model (CGE). The modelling of an economic pandemic using these two approaches might not offer accurate predictions especially for a developing country like Kenya. For one, CGE model is designed for supply side shocks and cannot assess demand side shocks, the model also assumes that the global economy is in equilibrium even in the midst of a pandemic or epidemic (Mitra-Kahn, 2008). Countries are already experiencing supply-demand imbalances emanating from panic buying of household items in the event that a lockdown directive is issued or for fear of contagion, it is hard to model this effect in a CGE models. The DSGE models on the other hand, are not very effective either as they do not contain sectorial details or are also underpinned on the principle of the economy reviving itself after a period of time (Stiglitz, 2018).

The purpose of this study therefore, is to fill this gap by assessing the potential effects of the pandemic on the economy. This is achieved by providing a comprehensive literature review of works that have been conducted on the impact of various global pandemics and the effects they have had on the economy. The paper also seeks to provide an understanding of the economic processes in times of a pandemic and provide insights into how the economy is likely to evolve. Finally, the paper offers policy recommendations on interventions that can be undertaken by the government to mitigate the effects of the exogenous shocks arising from the pandemic.

\subsection{Conduits of Impact}

Covid-19 is highly infectious and spreads through person to person, this factor makes it lethal. Moreover, the same attribute makes it more likely to have an adverse effect on the economy. 
Just like other contagious viruses causing flu like symptoms such as the Middle East Respiratory Syndrome hereafter MERS and Severe Acute Respiratory Syndrome hereafter SARS, Covid-19, impacts the economy through two distinctive conduits. The first, being the direct and indirect effects of the illness and the fatalities which consume and overwhelm the healthcare resources as well as a temporary and permanent loss of the labor force.

The second channel of impact is the behavioral effects that emerge from fear of contracting the disease. The behavior is manifested in terms of social distancing, lockdowns, self-quarantine among others meant to avoid contracting the virus. Other behavioral measures can be imposed by the government subsequently resulting in closure of businesses, reduction in participation in labor activities, disruption of the transport systems, and closure of points of entry particularly from the afflicted regions, plummeting in frequency of tourists as well as cancelation of flights. The same might also stem from the activities of the private sector who may close down businesses. The behavioral channel in turn disrupts domestic trade, leads to reduction in cargo ships, and postponement of business meetings. In the modern history of infectious diseases outbreaks such as MERS, SARS and Ebola, 85 percent of the total economic impacts of pandemics are associated with behavioral effect (World Bank Group, 2017). The two conduits of economic impact can be summarized in Figure 1 below.

The direct effect and indirect effect of an infectious epidemic is likely to cause more pressure on the government, and subsequently affect the health sector as well as other government sectors. The stress is likely to be caused by a proliferation of expenditures on health, deployment of security, and channeling of resources to social protection programs. The same is also likely to impact the private sector by paralyzing the food and animal production systems as well as the transportation system. Most of the damage to the economy however is as a result of behavioral effect, as this is less sensitive to infection rates and cases as it is underpinned by fear of association and contagion. The effect is more severe because it primarily relies on the spread of information about infections and public response to it. This is also likely to result to plummeting of revenue collected by the government due to reduced activities in the agriculture, transport services, and manufacturing. Additionally, the reduced economic activities will lead to a scarcity in food production resulting in malnutrition for some people and high cost of food items. Parallel to this, businesses will downsize laying workers off, and ultimately resulting in wage reductions (Schulze \& Wansink, 2012). 


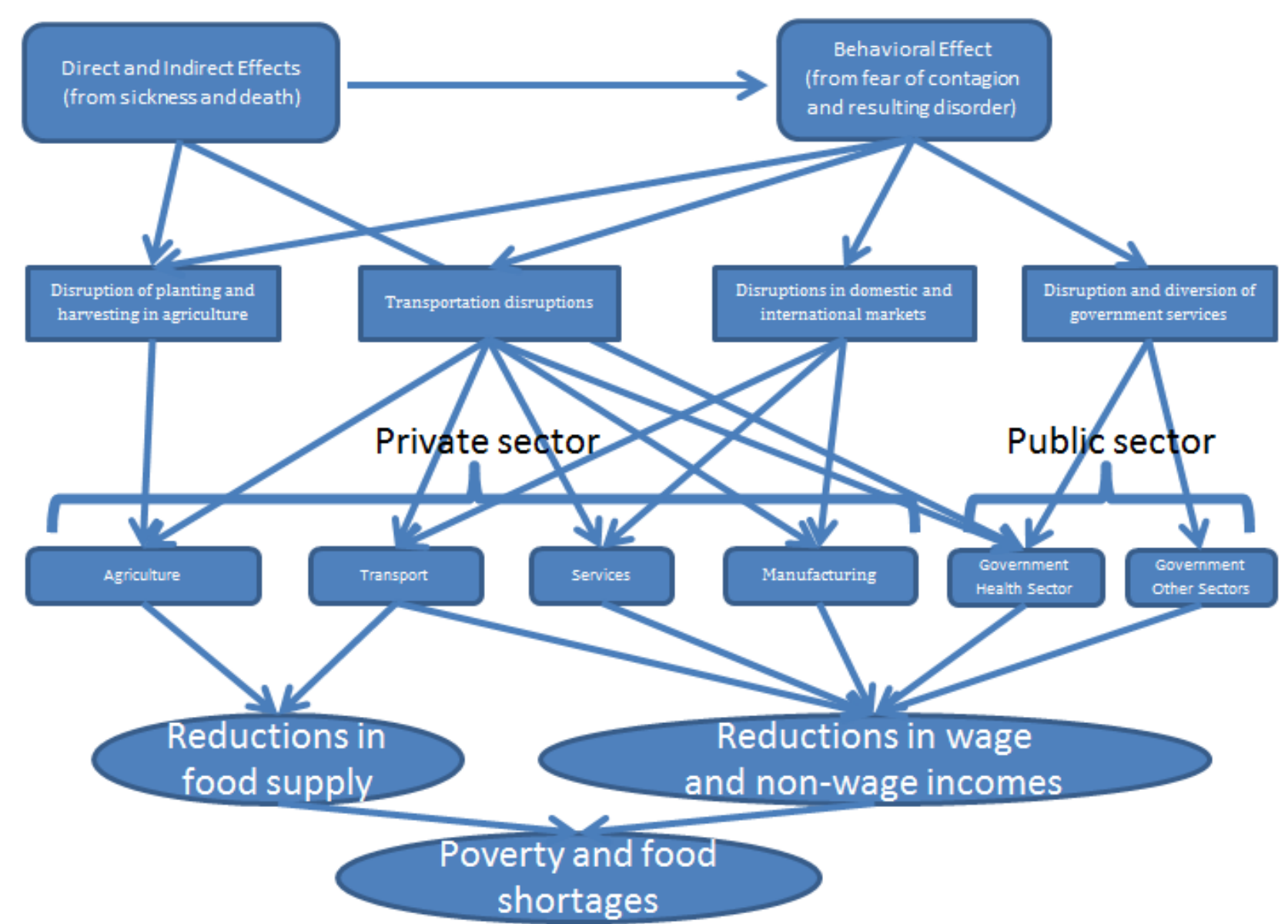

Fig 1: A Concept Map for Channels of Economic Impact of a Pandemic

Source: World Bank, (2014)

\section{Materials and Method}

This study used articles and reports that have widely discussed the effect of other epidemics that have occurred in contemporary times on the economy, specifically, SARS, MERS and Ebola. The study looked at analysis of peer reviewed studies published in referred journals and government working papers contained in the National Center for Biotechnology Information of the United States National Library of Medicine. Other articles reviewed were government works obtained from repositories of Chinese government institutions, South Korean government institutions, European Union, Centers for Disease Control and Prevention and The World Bank. The articles were considered authentic and, therefore, fit to be used in the study. Another criteria used to select the materials was based on the topic. The study specifically, focused on articles and studies in the field of health economics. The current study reviewed these works with the aim of getting an insight into the economic impact of an epidemic, particularly on tourism, travel and trade. The insights were then to shed light upon the possible impacts of the novel Covid-19 on Kenyan economy. This is vital in eliciting future discussions 
and analysis around the area of epidemics and their implications on the economy of developing countries.

\section{Literature Review}

\subsection{Impact on Tourism and Travels}

Reduction in international tourism and travels is undoubtedly one of the economic implication of infectious pandemics. The virus spread is likely to cause a $20 \%$ to $80 \%$ reduction in flights during the summit of infection spread. These percentages however vary based on the severity of the infections, the period of the pandemic and the number of countries affected (McKercher \& Chon, 2004). This section assesses some of the empirical works on the impact of a pandemic on tourism and travels.

Studies of the macroeconomic effects of the SARS epidemic in 2003 that lasted for about 7 months found significant effects on economies despite a relatively small number of cases and deaths. The global costs were significant and not limited to the directly affected countries. One of the areas worse affected was tourism and travel industry. Hong Kong recorded a 68\% decline in tourist arrivals one and a half months into the epidemic. Similarly, various airlines suffered major economic hits, Asia-pacific airline recorded a revenue loss of USD 6 billion, while North America airlines reported revenue losses of USD 1 billion (Economist, 2003). Canada reported 251 cases and 43 deaths, the epidemic resulted in a USD 4.3 billion in the hotel industry (KeoghBrown \& Smith, 2008). Singapore recorded a 71 percent drop in tourism which led to a compulsory unpaid leave of more than 6000 employees. Lufthansa saw demand for flights to and fro the Far East tumble 85 percent that year, and grounded a dozen planes. 80 percent of China's five-star hotels also made losses due to closure for the half year of 2003. These effects were largely attributed to behavioral effect of the epidemic such as minimized travels to affected countries, reduced visits to restaurants and bars, and avoidance of public transport (Begley, 2013).

MERS originated in Jeddah Saudi Arabia and caused an ephemeral outbreak in 2015, claiming over 791 people globally (Centers for Disease Control, 2016). Despite being brief, the resulting impact on the general global economy was enormous. In South Korea the outbreak of the disease resulted in quarantine of 16,000 people, 186 infections and 38 deaths. The epidemic led to a $40 \%$ decline in the number of international tourists in the first month and $61 \%$ in the second month. The decline led to a revenue loss of USD 10.5 billion in the tourism sector (Joo et al., 2019). Correspondingly, Saudi Arabia tourism Industry suffered a blow from the MERS epidemic mostly as a result of travel restrictions. Saudi Arabia's tourism authority reported a USD 5 billion loss in revenue. Mexico also took a hit and lost USD 3 billion in the tourism sector as a result of the epidemic. This was caused by the loss of over one million tourists and travelers (World Bank, 2017).

Ebola is another infectious disease whose 2014 outbreak impacted negatively the economies of the affected countries, mostly the West African countries. Among the worst hit states included Sierra Leone, Guinea and Liberia. According to a 2018 report by the World Health Organization, the 2014 outbreak proved to be grave compared to the previous outbreak since its discovery in 
1976. A total of 28652 individuals contracted the disease with a death toll of 28,652 . The epidemic lasted slightly over two years however, much of the damage was between July 2014 and May 2015. Just like every other contagious disease outbreak, the response was to avoid visiting these countries either due to fear or advisory by government. At the same time there were limited movement within the boundaries in a bid to avert its spread. A 2018 report by the World Travel and Tourism Council analyzed the effect of the epidemic on travel and tourism of the affected nations. Sierra Leone recorded a loss of USD 67 million accounting for 1.6\% decline in its contribution to the GDP. Guinea on the other hand, recorded a revenue loss of USD 75 million on tourism and travel, equaling $0.9 \%$ decline in contribution to GDP. The source also indicated that tourism in these economies are yet to bounce back to the pre-epidemic levels.

\subsection{Impact on Trade and Retail}

There are plenty of studies conducted that have attempted to evaluate the impact of epidemics on trade performance of countries. Most studies contend that businesses are more likely to take a hit due to curtailed movements of people. The 2003 SARS outbreak dampened the growth of many businesses in china. China's Bureau of Statistics reported a $0.8 \%$ reduction in GDP and this emerged from a dent in retail sector and a drop in exports of merchandize due to upsets in production that stemmed from the lockdown and shutting down of factories. The retail sector too recorded losses due to a decrease in consumer demand for products. Specifically, high tech manufacturing and retail industry experienced the heat of the epidemic. Globally, Oil demand reduced at an average of 3000 barrels per day in the first two months of the epidemic leading to a drop of oil prices by 15\% (Begley, 2013).

The MERS South Korean outbreak did not spare businesses in Korea and across the globe. The government of South Korea instituted several measures in a bid to decelerate the spread of the virus. It closed down public gatherings and events, slowed down daily activities and as a result, the country experienced a $10 \%$ fall in agricultural sector and hospitality industry's contribution to GDP. Similarly, entertainment and recreation sector were adversely affected as a result of the government's directive to have them closed during the epidemic time. The industry recorded an $8 \%$ sector contribution decrease to GDP, while printing sector recorded $6 \%$ decrease. There were some sectors that benefited from the pandemic, nonetheless. Supply stores recorded an accelerated growth which was attributed to panic buying by the masses and home deliveries services. Specifically, E-mart Company limited recorded a 63\% increase in profits while Home plus recorded a 50\% proliferation in sales revenue (Yun, 2015). However, export market for the products were affected, leading to a 0.3 drop in exports in the quarter that the epidemic was at peak (Li \& Cho, 2016).

The 2014 West Africa Ebola epidemic inhibited domestic trade in the wake of the outbreak. Trade was mainly curtailed due to restricted movements in the affected states. Cross border trade was also greatly affected as the adjusted countries closed their borders with Liberia, Sierra Leone and Gabon. The effect of the outbreak was felt by countries in other continents as well. USA exports to these countries reduced by USD 1.8 billion in 2015 and 12,200 job losses associated with exports to these areas (Kostova et al., 2019). 


\section{Kenyan Level Initiatives}

Kenya reported its first case of Covid-19 on March 13 ${ }^{\text {th }} 2020$, a 27-year-old Kenyan traveler who jetted in the country from the USA via London. The infection rate of the virus has been on the rise ever since. At the time of writing this document the number of confirmed cases stands at 110, with 4 recovery cases, and 3 deaths. The minister of health reported that the spread is bound to skyrocket in the months of April and May.

In an effort to curb the spread of the virus, the Kenyan government instituted a number of measures, both behavioral and economic. The behavioral measures included an indefinite closure of recreational facilities such as bars and amusement parks; imposition of a dusk to dawn curfew; ban of public gatherings and events; issuance of a directive to Public Service Vehicles to implement social distancing among passengers; as well as suspension of international flights from landing or flying out of Kenya with the exception of cargo flights.

The government instituted monetary policy measures through the Monetary Policy Committee to avert a possible case of recession. These measures included a reduction in the cash reserve ratio by 1 percentage point, from $5.25 \%$ to $4.25 \%$; a reduction of interest rate by a 1 percentage point, from $8.25 \%$ to $7.25 \%$. Fiscal measures were also undertaken, they included, corporate income tax reduction from $30 \%$ to $25 \%$; individual income tax reduction from $30 \%$ to $25 \%$; $100 \%$ tax waiver to individuals earning less than USD 240; VAT reduction from $14 \%$ to $16 \%$; injection of a USD 10 million social protection stimulus package for the elderly and underprivileged citizens; and a temporary delisting of loan defaulters from the Credit Reference Bureau.

\section{Discussion}

Kenya recorded remarkable performance in tourism in 2019. The total revenue realized by the sector was USD 1.63 million and international tourist arrivals stood at 2, 048, 834 down from $2,025,206$ in 2018. With the initiative by the government to suspend international flights, and closure of many hostels and restaurant the sector is likely to take a hit. The impact is however, dependent on the duration of the pandemic. If the situation lasts for only one quarter since the reporting of the first case, the pandemic will have a mild effect on the sector. In this scenario, there is a likelihood of a less than $20 \%$ revenue loss. This can be justified by the fact that Kenya receives a low number of tourist arrival in the first and second quarter. According to the literature reviewed the countries that are epicenters of an epidemic usually take a longer time to rebound, however, the case is likely to be different with Kenya since it has a relatively lower levels of the infection cases. On the other hand, in the event that the pandemic is persistent and lasts till December 2020 or extends to 2021, then the pandemic will have a dampening effect on the tourism sector with a more than $80 \%$ reduction in the revenues.

Trade will also take a hit however, the impact will not be very severer. Kenya's government has not suspended the landing and take-off of cargo flights. This indicates that goods can leave and enter the country. Imports of high-technology, retail and merchandize are expected to plummet, especially from worst affected countries such as Italy, China, and South Korea. The reason for this is that most of the affected countries have closed their ports and productions levels have 
significantly diminished. The imports reduction will be exacerbated by the possibility of individuals postponing high investment projects such purchasing of cars, computers and phones in a bid to save for uncertain times ahead. Trade in services will significantly reduce; consumption abroad and commercial presence modes of trade in services will be constrained due to the closure of borders.

Locally, there will be reduction in retail trade of merchandise. The government directive of minimizing movement and risk aversion behavior by citizens will upset production and supply chains in the retail industry. Supply effects will arise from reduction of working hours due to the dusk to dawn curfew. However, the supply side effects, stemming from depressed efficiency of employees, as a result of sickness are not likely to be felt considering the effect of the virus is not homogenous across the age groups. Demand effects are likely to occur because of closure of the entertainment and recreational establishments. The demand shock on retail trade is, however, expected to be smaller than the supply shock because of the monetary policy measures imposed by the government. These measures include reduction of interest rates by 1 percentage point, delisting of defaulters and reduction of cash reserve ratio. According to Tyler rule, reduction in interest rate by central bank is likely to suppress the negative effect on consumption spending. This will ensure that individuals have access to credit and thus purchase food supplies and other basic needs. Furthermore, the demand effects are likely to be less because people will halt the purchase of expensive goods and long-term projects. The additional savings will be spent after the pandemic.

Pharmaceutical sector is likely to face a disruption of supply. The oil and energy sector will experience sluggish growth due to limited transportation activities. Retail of agricultural produce will be strained due to low production, there are high chances of depletion of strategic food reserves before the end of the second quarter. Some retail sectors however, are expected to record impressive performance. These include, the Taxi industry and private car hire companies as people will avoid public transport due to fear of contracting the disease. Online retailers will gain especially those that do home delivery of household items and food. The demand for masks will go up, hand sanitizers and soap businesses will see increased volume of sales.

\section{Conclusions and Policy Implications}

The initiatives taken by the Kenyan government to combat the Covid-19 are key in decelerating the adverse effects of the pandemic. The primary goal is to avert the spread of the virus and ensure that human health is given the first priority and everything else come second to it. The initiatives are likely to have a far reaching implication to the economy, particularly on tourism and trade. Still, a plethora of policy responses will be required both in the short term as well as in the long term. The short term policies that have been pursued so far seem to be effective, especially a reduction of interest rates and suspension of loan defaulters from the credit reference bureau. It is worth noting however, that the pandemic shock on the economy and by extension trade is not just a demand problem but an all-encompassing problem that will require a multisectoral approach. There is a need, therefore, for a deliberate partnership among stakeholders from all the sectors such as, health, treasury, trade, tourism, private sector and civil 
society to chart the way forward on the management of the pandemic shocks. Secondly, after the pandemic, the Kenyan government, through Brand Kenya should embark on massive campaigns to appeal to tourists to visit the country and restore the tourism sector back to its equilibrium. Locally, the tourism industry players should strive to promote domestic tourism by carrying out aggressive marketing campaigns and sensitizing to the local tourists about attractive domestic destinations.

Long term policies should pay attention to increased investments in the health sector especially on intensive care units, medical facilities and pharmaceutical products. It will also be critical to improve the public health and sanitation situation in the country to minimize chances of future communicable and highly infectious diseases. A robust and efficient health care system will go a long way to ensure that the population remains healthy and contribute more to the economy through increased production. Secondly, long term policies should focus on increased production through massive investment in the manufacturing sector. The government should also consider mechanization of agriculture to boost food supply in the country. These policies will ensure that the country remains self-sufficient in terms of disease pandemics and epidemics.

Conflicts of Interest: The author declares no conflict of interest.

\section{REFERENCES}

Bateman, J. (2016). The Trade Show of Everything, https://www.theatlantic.com/business/archive/2016/05/cantonfair-guangzhou-everything/483545/, (Accessed March 29, 2020).

Begley, S. (2013) Flu-Conomics: The Next Pandemic Could Trigger Global Recession https://www.reuters.com/article/us-reutersmagazine-davos-flu-economy/flu-conomics-the-next-pandemiccould-trigger-global-recession-idUSBRE90K0F820130121 (accessed April 1, 2020).

Castro, M. F. (2020). Fiscal Policy during a Pandemic. Federal Reserve Bank of St. Louis. Working Paper 2020-006C

Centers for Disease Control and Prevention (2019). Middle East Respiratory Syndrome (MERS). http://www.cdc.gov/coronavirus/mers/about/index.html. (Accessed April 2, 2020)

EFlein John (2020). Infection rates of viruses that caused major outbreaks worldwide as of 2020. Statistica retrieved from https://www.statista.com/statistics/1103196/worldwide-infection-rate-of-major-virus-outbreaks/ (Accessed March 28, 2020)

Joo, H., Maskery, B. A., Berro, A. D., Rotz, L.D., Lee, Y. K, \& Brown, C. M. (2019). Economic Impact of the 2015 MERS Outbreak on the Republic of Korea's Tourism-Related Industries. Health Security, 17(2), 100-108

Joseph E Stiglitz, (2018). Where modern macroeconomics went wrong, Oxford Review of Economic Policy, 34 (1-2), 70106.

Keogh-Brown, M. R, \& Smith, R.D (2008). The economic impact of SARS: how does the reality match the predictions? Health Policy 88(1), 110-120

Korea Centers for Disease Control and Prevention (2015). Middle East respiratory syndrome coronavirus outbreak in the Republic of Korea, 2015. Osong Public Health Res Perspect 6(4), 269-278

Kostova, D., Cynthia H., Redd, T. J., Williams, D. E., Tushar S., Martel, D. L, \& Bunnell E. R. (2019). Long-distance effects of epidemics: Assessing the link between the 2014 West Africa Ebola outbreak and U.S. exports and employment. Health Economics, 28(11), 1248-1261

Lee, A \& Cho, J. (2016). The impact of epidemics on labor market: identifying victims of the Middle East respiratory Syndrome in the Korean labor market, Int. J. Equity Health15, 196

Lee, C. \& Ki, M. (2015). Strengthening epidemiologic investigation of infectious diseases in Korea: lessons from the Middle East respiratory Syndrome outbreak, Epidemiol Health, 37, 1-8 
McKercher, B. \& Chon, K. (2004). The over-reaction to SARS and the collapse of Asian tourism, Annals of Tourism Research, 31(3), 716-719.

McKibbin, W \& Fernando, R. (2020). The Global Macroeconomic Impacts of COVID-19: Seven Scenarios. Discussion Paper

Mitra-Kahn, B. H. (2008). Debunking the Myths of Computable General Equilibrium Models. Schwartz Center for Economic Policy Analysis and Department of Economics. The New School for Social Research, Working Paper Series.

Schulze, W. \& Wansink, B. (2012), Toxics, Toyotas and terrorism: The behavioral economics of fear and stigma, Risk Analysis, 32(4), $678-694$.

The Economist (2003), Painful Side Effects. https://www.economist.com/news/2003/05/05/painful-side-effects (accessed April 1, 2020).

The World Health Organization (2018). Ebola Virus Disease Key Facts (12th February 2018)

The World Health Organization (2020). Coronavirus disease (COVID-2019) situation report-103. https://www.who.int/docs/default-source/coronaviruse/situation-reports/20200502-covid-19-sitrep103.pdf?sfvrsn=d95e76d8 4 (accessed May 2, 2020).

World Bank (2014). The economic impact of the 2014 Ebola epidemic: short and medium term estimates for West Africa, The World Bank Group, 2014.

World Bank (2017). From panic and neglect to investing in health security: financing pandemic preparedness at a national level. World Bank Group, 2017.

World Travel \& Tourism Council (2018). Impact of the Ebola epidemic on Travel \& Tourism, Working Paper, December.

Yun, S. (2015). Schools Reopen as South Korea Seeks Normality amid MERS https://www.reuters.com/article/ushealth-mers-southkorea-idUSKBN0OU14P20150615 (Accessed April 2, 2020). 